\title{
Hybrid active damping of LCL-filtered grid connected converter
}

\author{
Abdelhady Ghanem ${ }^{1,2}$, Mohamed Rashed ${ }^{1,2}$, Mark Sumner ${ }^{1}$ \\ ${ }^{1}$ Department of Electrical and Electronics Engineering \\ University of Nottingham \\ Nottingham, UK. \\ eexatg@nottingham.ac.uk
}

\begin{abstract}
A method for hybrid active damping in power converters connected to a weak grid using an $L C L$ filter is proposed. It uses feedback of the grid current and capacitor voltage and is derived as an equivalent to the capacitor current feedback active damping method. A co-design procedure for the grid current controller with the proposed hybrid active damping method is presented. The robustness, system bandwidth and harmonic rejection are studied. The proposed method is applied to a single grid connected converter with variable grid inductance to investigate its ability to damp different system resonance frequencies and its effectiveness is verified via frequency domain analysis and time domain simulation.
\end{abstract}

Keywords-Hybrid active damping; grid current control; variable resonant damping; weak grid.

\section{INTRODUCTION}

Grid connected converters commonly use voltage source inverters (VSI) and are controlled by regulating the injected current [1]. To reduce the switching frequency ripple and improve the quality of the injected current, an $L$-filter or $L C L$ filter is usually adopted between the converter and the grid [2]. $L C L$-filters provide better attenuation of high-order harmonics [3]. However, due to the resonance that can be created by the $L C L$ filter, damping solutions are needed to stabilize the system [2]. In addition, the inclusion of $L C L$-filters with three-phase VSIs complicates the current control design [3]. By analysing the virtual impedance introduced by the control system, it is found that the single loop grid current control introduces a frequency dependent virtual impedance comprising a parallel resistance and capacitance in parallel with the filter capacitor and its magnitude is proportional to the current control loop gain [4]. The virtual resistance is only positive when the frequency is greater than $f_{s} / 6$ (where $f_{s}$ is the sampling frequency) and the system is stable if the resonance frequency falls into this frequency range. Additionally, the virtual parallel capacitance that is introduced is positive below $f_{s} / 3$. It means in this frequency range, the resonance frequency will decrease as current control gain increases and instability can be seen. Therefore, the current control gain should be small to alleviate the effect of the virtual capacitance which will lead to a tradeoff between the system dynamic performance and stability range. In addition, the system performance will be sensitive to the grid impedance.

Damping of $L C L$ resonance is generally classified as passive and active. Passive methods are based on adding a passive damping resistor to the $L C L$ filter but tend to be avoided due to additional

\author{
Mohamed Adel Elsayes ${ }^{2}$, I. I. I. Mansy ${ }^{2}$ \\ ${ }^{2}$ Electrical Engineering Department \\ Mansoura University \\ Mansoura, Egypt.
}

losses $[5,6]$. Active damping methods are preferred providing sufficient damping via cascading a digital filter with the current controller or feeding back additional filter variables [7]. Active damping based on digital filters represents a sensor-less technique; however, it is sensitive to parameter variation [8]. Feedback type active damping uses capacitor current [2, 9-13], capacitor voltage $[14,15]$, grid current $[16,17]$ or combinations $[5,18,19]$ as an inner feedback for damping resonance. Among these feedback variables, the filter capacitor current is widely chosen, however, the additional current sensor increases the cost and reduces reliability. Active damping based on grid current feedback with negated high pass filter (HPF) reduces the number of sensors required [16, 17]. However, the active damping feedback loop is tuned to address a specific $L C L$ resonance frequency using predefined filter parameters and cannot deal with variations of the resonance frequency without retuning the damping loop. Capacitor voltage is always measured for grid synchronization and therefore can be used for active damping avoiding the need for an extra sensor. However, a derivative term is required which will lead to noise amplification [20].

This paper proposes the use of a hybrid active damping method based on grid current and capacitor voltage feedback derived as an equivalent to capacitor current based active damping. This method helps to modify the passivity of the converter output admittance to damp the resonance frequency over a wide range. The proposed hybrid active damping has the following features: simple implementation, cost effective, high reliability and insensitive to grid parameters variation.

\section{SYSTEM DESCRIPTION}

Fig. 1 shows the simplified single line diagram of a three-phase grid connected converter with an $L C L$ filter. Grid current is controlled and the capacitor voltage is measured for grid synchronization. Both the grid current and capacitor voltage are also used for active damping.

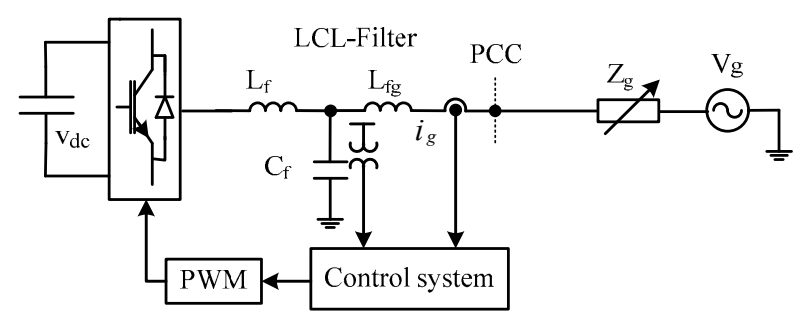

Fig. 1. Configuration of LCL filtered grid connected converter. 
The transfer function of converter output voltage and voltage at PCC to the grid current, capacitor voltage and capacitor current can be obtained from the $L C L$ filter model shown in Fig. 2 as:

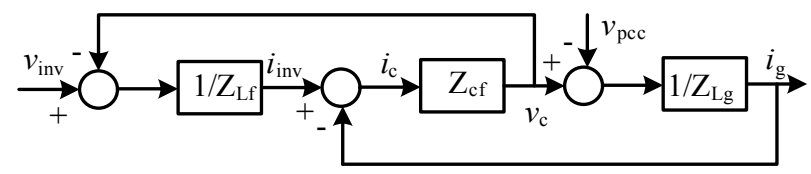

Fig. 2. LCL filter model.

$$
\begin{aligned}
& i_{g}=G_{v_{i n v}}^{i_{g}} v_{i n v}+G_{v_{p c c}}^{i_{g}} v_{p c c} \\
& v_{c}=G_{v_{i n v}}^{v_{c}} v_{i n v}+G_{v_{p c c}}^{v_{c}} v_{p c c} \\
& i_{c}=G_{v_{\text {inv }}}^{i_{c}} v_{i n v}+G_{v_{p c c}}^{i_{c}} v_{p c c}
\end{aligned}
$$

where;

$$
\begin{gathered}
G_{v_{\text {inv }}}^{i_{g}}=\frac{1}{L_{f} L_{f g} C_{f} s\left(s^{2}+\omega_{r e s}^{2}\right)}, \quad G_{v_{i n v}}^{v_{c}}=\frac{1}{L_{f g} C_{f}\left(s^{2}+\omega_{r e s}^{2}\right)} \\
G_{v_{i n v}}^{i_{c}}=\frac{s}{L_{f}\left(s^{2}+\omega_{r e s}^{2}\right)}, \quad G_{v_{p c c}}^{i_{g}}=-\frac{L_{f} C_{f} s^{2}+1}{L_{f} L_{f g} C_{f} s\left(s^{2}+\omega_{r e s}^{2}\right)} \\
G_{v_{p c c}}^{v_{c}}=\frac{1}{L_{f g} C_{f}\left(s^{2}+\omega_{r e s}^{2}\right)}, \quad G_{v_{p c c}}^{i_{c}}=\frac{s}{L_{f g}\left(s^{2}+\omega_{r e s}^{2}\right)} \\
\omega_{r e s}=\sqrt{\frac{L_{f}+L_{f g}}{L_{f} L_{f g} C_{f}}}
\end{gathered}
$$

The block diagram of the grid connected converter without damping (single loop control) is shown in Fig. 3. The open loop transfer function of the grid current control without active damping is given by:

$$
G_{\text {ol-single }}=G_{i}(s) G_{\text {inv }}(s) G_{v_{\text {inv }}}^{i_{g}}(s)
$$

In order to eliminate the current steady-state error at the fundamental frequency $\omega_{n}$, a Proportional-Resonant (PR) current controller, $G_{i}(s)$ with a proportional gain of $k_{p}$, and a resonance gain of $k_{i}$ is adopted as given by (5). $G_{i n v}(s)$ is the converter equivalent computational delay as shown in (6).

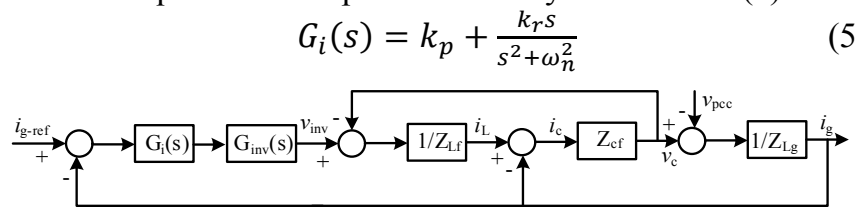

Fig. 3. Block diagram of grid connected converter control without damping.

$$
G_{i n v}(s)=e^{-1.5 T_{S} s}
$$

Fig. 4 shows the bode plot of the open loop transfer function for the grid current control system without active damping at different resonance frequencies created by changing the grid inductance value. It can be seen that the system will be stable if the resonance frequency is in the frequency range of $f_{s} / 6$ to $f_{s} / 2$ while it is unstable below $f_{s} / 6$. Therefore, for operation below this critical frequency $f_{s} / 6$, damping is required.

\section{Proposed Hybrid Active DamPING Method}

\section{A. Derivation of the proposed active damping method}

The block diagram of grid connected converter with a capacitor current active damping loop is shown in Fig. 5.

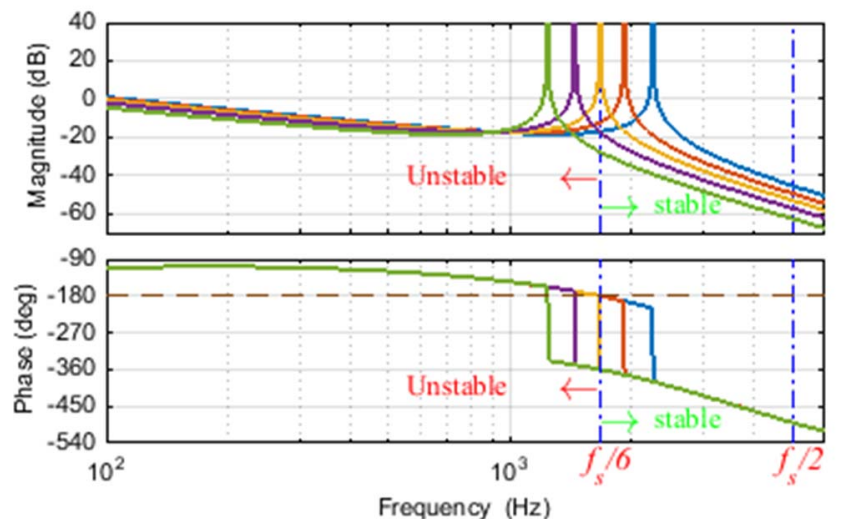

Fig. 4: Bode plot of the open loop TF, $G_{\text {ol-single }}$.

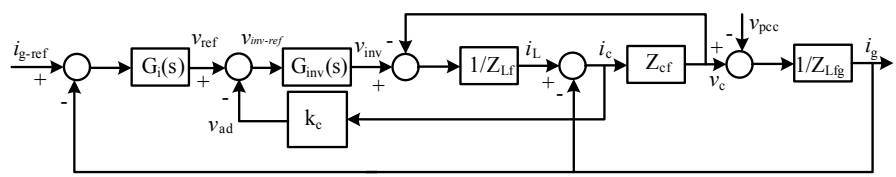

Fig. 5. Block diagram of grid connected converter control with capacitor current feedback active damping.

The transfer function from the inverter output voltage to the grid current with capacitor current active damping is:

$$
G_{v_{i n v-a d}}^{i_{g}}(s)=\frac{1}{L_{f} L_{f g} C_{f} s\left(s^{2}+\frac{k_{C}}{L_{f}} s+\omega_{r e s}^{2}\right)}
$$

The capacitor current and the active damping equivalent voltage $v_{a d}$ as a function of the inverter output voltage, capacitor voltage and grid current are:

$$
\begin{aligned}
& i_{c}=i_{L}-i_{g}=\frac{1}{z_{L f}}\left(v_{i n v}-v_{c}\right)-i_{g} \\
& v_{a d}=k_{c} i_{c}=\frac{k_{c}}{z_{L f}}\left(v_{i n v}-v_{c}\right)-k_{c} i_{g}
\end{aligned}
$$

Based on the block diagram shown in Fig. 5 and $(8,9)$, the inverter output voltage can be written as:

$$
\begin{gathered}
v_{\text {inv-ref }}=v_{r e f}-v_{a d} \\
\therefore v_{\text {inv-ref }}=\frac{v_{r e f}}{1+\frac{k_{c}}{s L_{f}}}+v_{c} \frac{k_{c}}{s L_{f}} \frac{1}{1+\frac{k_{c}}{s L_{f}}}+i_{g} \frac{k_{c}}{1+\frac{k_{c}}{s L_{f}}} \\
\therefore v_{\text {inv-ref }}=v_{\text {ref }} \frac{s}{s+\omega_{h}}+v_{c} \frac{\omega_{h}}{s+\omega_{h}}+i_{g} \frac{k_{c} s}{s+\omega_{h}}
\end{gathered}
$$

The first term of (12) represents the output of the current controller followed by a HPF. Note that this HPF can degrade the system disturbance rejection. Therefore, this HPF can be eliminated and the inverter output voltage can be rewritten as (13). The second and third terms of (12) represent the equivalent active damping voltage based on the capacitor voltage and grid current feedback. The capacitor voltage feedback loop has a LPF and the grid current feedback loop has a HPF and both of them represent a positive feedback.

$$
\therefore v_{\text {inv-ref }} \cong v_{\text {ref }}+v_{c} \frac{\omega_{h}}{s+\omega_{h}}+i_{g} \frac{k_{c} s}{s+\omega_{h}}
$$

where, $\omega_{h}=\frac{k_{c}}{L_{f}}, \quad Z_{L f}=s L_{f}$.

The transfer function from the inverter output voltage to the grid current with the hybrid active damping loops is:

$$
G_{v_{i n v-a d}}^{i_{g}}(s)=\frac{s+\omega_{h}}{s^{2}\left(L_{f} L_{f g} C_{f} s^{2}+L_{f} L_{f g} C_{f} \omega_{h} s+L_{f}+L_{f g}\right)}
$$


It is worth mentioning that, the presence of the term $s^{2}$ in the actively damped transfer function will introduce a constant phase of $-180^{\circ}$ in the open loop frequency response. As a result, the phase margin will be degraded and instability may occur. In addition, the cut-off frequency of the filters should be high to insure wideband system passivity. Therefore, for grid current active damping, the cut-off frequency should be close to and higher than the resonance frequency to maximize the damping $[16,17]$. It means the damping from the grid current loop will be degraded if the cut-off frequency is far from the resonance frequency. To overcome this problem, the capacitor voltage active damping loop is followed by a HPF instead of a LPF and filter gains are included. This helps to reduce the effect of the active damping on the fundamental component and allows separate design of the active damping loops. The feedback active damping loop is modified as:

$$
v_{a d}=v_{c} \frac{k_{a d v} s}{s+\omega_{a d v}}+i_{g} \frac{k_{a d i} s}{s+\omega_{a d i}}=v_{c} G_{a d v}(s)+i_{g} G_{a d i}(s)
$$

The block diagram of the grid connected converter with the proposed active damping system is shown in Fig. 6. The transfer function from the inverter output voltage to the grid current with the modified hybrid active damping loop is given by (16).

$G_{v_{\text {inv-mod }}}^{i_{g}}(s)=$ $\left(s+\omega_{a d v}\right)\left(s+\omega_{a d i}\right)$

$\overline{L_{f} L_{f g} C_{f} s\left(s^{2}+\omega_{r e s}^{2}\right)\left(s+\omega_{a d v}\right)\left(s+\omega_{a d i}\right)-k_{a d v} L_{f g} s^{2}\left(s+\omega_{a d i}\right)-k_{a d i} s\left(s+\omega_{a d v}\right)}$

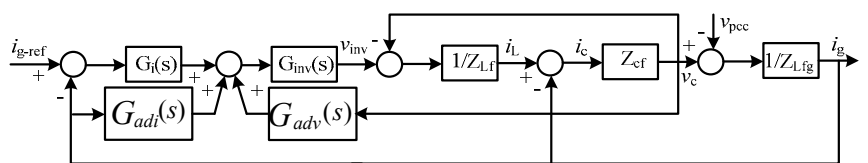

Fig. 6. Block diagram of grid connected converter control with the proposed hybrid active damping.

\section{B. Generalized impedance model of grid connected converter:}

From the closed loop control shown in Fig. 6 and the model of the $L C L$ filter given in section II, the closed loop behaviour of the grid connected converter (Norton equivalent model) including the proposed active damping loop is:

$$
i_{g}=G_{e q} i_{\mathrm{g}-\mathrm{ref}}-Y_{e q} v_{p c c}
$$

where;

$G_{e q}=$

$$
\begin{aligned}
& \frac{G_{i}(s) G_{i n v}(s) G_{v_{i n v}}^{i_{g}}(s)}{1+G_{i}(s) G_{i n v}(s) G_{v_{i n v}}^{i_{g}}(s)-G_{a d i}(s) G_{i n v}(s) G_{v_{i n v}}^{i_{g}}(s)-G_{a d v}(s) G_{i n v}(s) G_{v_{i n v}}^{v_{c}}(s)} \\
& Y_{e q}= \\
& \frac{-G_{a d v}(s) G_{i n v}(s) G_{v_{i n v}}^{i_{g}}(s) G_{v_{p c c}}^{v_{c}}(s)-G_{v_{p c c}}^{i_{g}}(s)+G_{a d v}(s) G_{i n v}(s) G_{v_{p c c}}^{i_{g}}(s) G_{v_{i n v}}^{v_{c}}(s)}{1+G_{i}(s) G_{i n v}(s) G_{v_{i n v}}^{i_{g}}-G_{a d i}(s) G_{i n v}(s) G_{v_{i n v}}^{i_{g}}(s)-G_{a d v}(s) G_{i n v}(s) G_{v_{i n v}}^{v_{c}}(s)}
\end{aligned}
$$

Including the grid impedance $Z_{g}$, the generalized impedance based equivalent circuit of the grid connected converter is shown in Fig. 7. The overall closed loop response including the effect of grid impedance is given by:

$$
\begin{aligned}
& i_{g}=G_{c l} i_{\mathrm{g}-\mathrm{ref}}-Y_{c l} v_{g} \\
& \text { where; } G_{c l}=\frac{G_{e q}}{1+Y_{e q} z_{g}}, \quad Y_{c l}=\frac{Y_{e q}}{1+Y_{e q} z_{g}}
\end{aligned}
$$

And the open loop transfer function can be obtained as:

$$
G_{o l}=\frac{G_{e q}}{1+Y_{e q} Z_{g}-G_{e q}}
$$

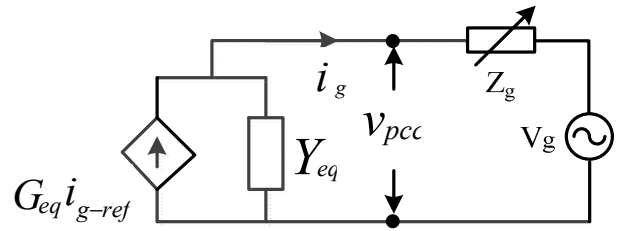

Fig. 7. Impedance based equivalent model of grid connected converter.

\section{CO-DESIGN OF THE CURRENT CONTROLLER AND THE PRPOSED HYBRID ACTIVE DAMPING METHOD}

This section presents the co-design of the grid current controller and active damping loops. First, to avoid low frequency resonance and to ensure high positive output admittance range, the grid current active damping loop is designed to deal with the frequency around the $L C L$ resonance frequency based on the design guide lines recommend in $[16,17]$. Therefore, the cut off frequency of the high pass filter $\omega_{a d i}$ is set at 0.3 of the sampling frequency. Secondly, the capacitor voltage active damping loop is designed as the grid current active damping loop is a part of the control system. The cut off frequency of the capacitor voltage loop $\omega_{a d v}$ is selected at 0.01 of the sampling frequency to remove the fundamental component. The grid current $k_{\text {adi }}$, and capacitor voltage $k_{a d v}$ gains of the active damping loops and the grid current controller gain $k_{p}$ are selected based on the root loci of the discrete z-domain model.

\section{A. Discrete z-domain model}

Fig. 8 illustrates the grid current control diagram in the discrete $z$-domain, where $Z_{g t}$ represent the combination of $Z_{f g}$ and $Z_{g}$. A $Z O H$ block and $Z^{-1}$ are included for modelling the digital PWM and computational delays [21]. The PR current controller $G_{i}(s)$ is discretised using the Tustin transformation pre-warped at the fundamental frequency. The grid current active damper $G_{a d i}(s)$ and the capacitor voltage active damper $G_{a d v}(s)$ are discretised by applying the Tustin transformation while the plant transfer functions $G_{v_{\text {inv }}}^{i_{g}}(s)$ and $G_{v_{\text {inv }}}^{v_{c}}(s)$ are discretised by applying the $\mathrm{ZOH}$ transformation.

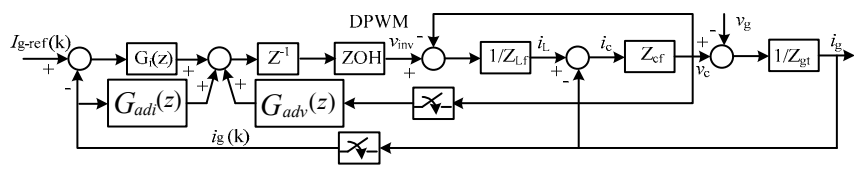

Fig. 8. Block diagram of grid connected converter control with the proposed hybrid active damping in $z$-domain.

The open loop $G_{o l}(z)$ and closed loop $G_{c l}(z)$ transfer functions of the grid current control with hybrid active damping are:

$$
\begin{gathered}
G_{o l}(z)=\frac{z^{-1} G_{i}(z) G_{v_{i n v}}^{i_{g}}(z)}{1-z^{-1} G_{a d i}(z) G_{v_{i n v}}^{i_{g}}(z)-z^{-1} G_{a d v}(z) G_{v_{i n v}}^{v_{c}}(z)} \\
G_{c l}(z)=\frac{z^{-1} G_{i}(z) G_{v_{i n v}}^{i_{g}}(z)}{1+z^{-1} G_{i}(z) G_{v_{i n v}}^{i_{g}}(z)-z^{-1} G_{a d i}(z) G_{v_{i n v}}^{i_{g}}(z)-z^{-1} G_{a d v}(z) G_{v_{i n v}}^{v_{c}}(z)}
\end{gathered}
$$

where;

$$
\begin{gathered}
G_{i}(z)=k_{p}+\frac{k_{r} \sin \left(\omega_{1} T_{s}\right)\left(z^{2}-1\right)}{2 \omega_{1}\left[z^{2}-2 z \cos \left(\omega_{1} T_{s}\right)+1\right]} \\
G_{v_{\text {inv }}}^{v_{c}}(z)=\frac{\left[1-\cos \left(\omega_{\text {res }} T_{s}\right)\right](z-1)}{L_{f} C_{f} \omega_{r e s}^{2}\left[z^{2}-2 z \cos \left(\omega_{\text {res }} T_{s}\right)+1\right]}
\end{gathered}
$$




$$
\begin{aligned}
G_{v_{\text {inv }}}^{i_{g}}(z)= & \frac{T_{s}}{\left(L_{f}+L_{g t}\right)(z-1)} \\
& -\frac{(z-1) \sin \left(\omega_{\text {res }} T_{s}\right)}{\left(L_{f}+L_{g t}\right) \omega_{\text {res }}\left[z^{2}-2 z \cos \left(\omega_{\text {res }} T_{s}\right)+1\right]} \\
G_{\text {adi }}(z) & =\frac{2 k_{\text {adi }}(z-1)}{z\left(\omega_{a d i} T_{s}+2\right)+\left(\omega_{\text {adi }} T_{s}-2\right)} \\
G_{\text {adv }}(z) & =\frac{2 k_{\text {adv }}(z-1)}{z\left(\omega_{a d v} T_{s}+2\right)+\left(\omega_{a d v} T_{s}-2\right)}
\end{aligned}
$$

\section{B. Control system design procedures}

The co-design procedures are formulated as follows:

1. For simplicity, the current controller is assumed to be proportional gain only; the resonant term of the PR resonant controller is designed to achieve zero steady state error at fundamental frequency and its effect at higher frequency is small [22]. The cut-off frequency of the grid current active damping is set at $0.3 \omega_{s}$ to achieve highest passivity range.

2. The grid current active damping is then designed to damp the frequency resonance related to the $L C L$ filter $\left(L_{g}=0\right)$ based on the root locus when the distance between the conjugate poles in $z$-domain is minimum.

3. Based on the parameters from step 2, the capacitor voltage loop is designed at $f_{\text {res }}=f_{s} / 6$ with cut-off frequency 0.01 $\omega_{s}$ to remove the fundamental component and the grid current active damping loop is a part of the system. The proportional current controller gain and the capacitor voltage active damping loop gain are selected based on the minimum distance between the conjugate poles in $z$-domain.

The root loci of the closed loop system using the parameter listed in Table I and the proposed design are shown in Fig. 9. The optimal root contours that represent the minimum distance between conjugate poles are marked by " $x$ ". From Fig. 9-a it is found that the optimal value of $k_{\text {adi }}$ is 10 and from Fig. 9-b the optimal value of $k_{a d v}$ and $k_{p}$ are 0.7 and 15.5 respectively. Fig. 10 shows the bode plot of the open loop transfer function with the proposed hybrid active damping with the designed parameters at different grid inductance values. It can be seen that the system is stable for a wide range of the grid inductances, the resonance peak is always less than $0 \mathrm{~dB}$ and the damping increases as the grid becomes weak. It is worth noting that, for a very strong grid $\left(L_{g}=0\right)$ the resonance peak is more than $0 \mathrm{~dB}$. However the presence of parasitic resistances (which are ignored in this work) will increase the damping of this resonance peak.

Table I. System parameters.

\begin{tabular}{|c|c|}
\hline Grid voltage, $V_{g L-L}$ & $400 \mathrm{~V}$ \\
\hline Grid frequency, $f_{l}$ & $50 \mathrm{~Hz}$ \\
\hline Converter-side filter inductor, $L_{f}$ & $5 \mathrm{mH}$ \\
\hline Grid-side filter inductor, $L_{f g}$ & $1 \mathrm{mH}$ \\
\hline Filter capacitor, $C_{f}$ & $6 \mu \mathrm{F}$ \\
\hline Switching frequency, $f_{s w}$ & $10 \mathrm{kHz}$ \\
\hline Sampling frequency, $f_{s}$ & $10 \mathrm{kHz}$ \\
\hline Resonant gain $\left(\mathrm{G}_{\mathrm{i}}\right), k_{r}$ & 600 \\
\hline
\end{tabular}

System bandwidth and phase margin are also investigated and presented as shown in Fig. 11. It can be seen that the system bandwidth decreases as the grid becomes weak, however a harmonic compensator can be included with the fundamental component PR controller to improve the injected grid current without degrading system stability. It is also clear that phase margin increases as the grid inductance increases which means the system response becomes slow, however it is within the typical range of $30^{\circ}-60^{\circ}$ as recommended in [23].

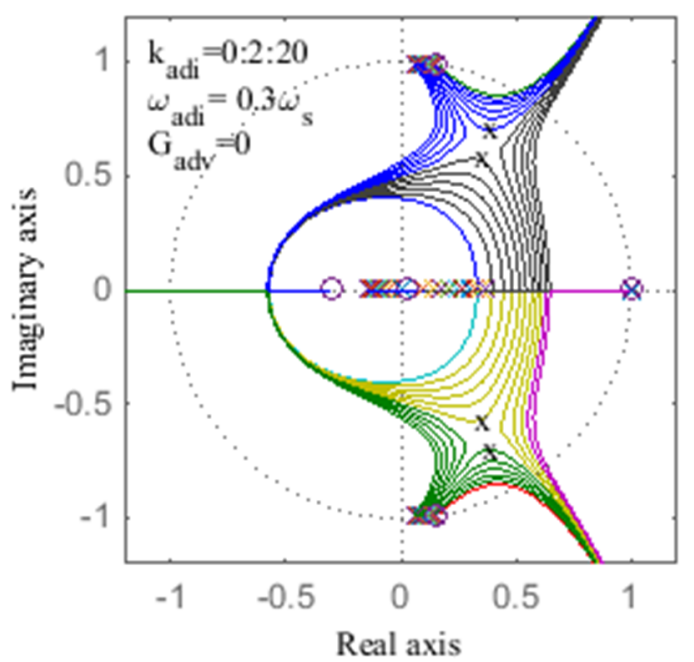

(a)

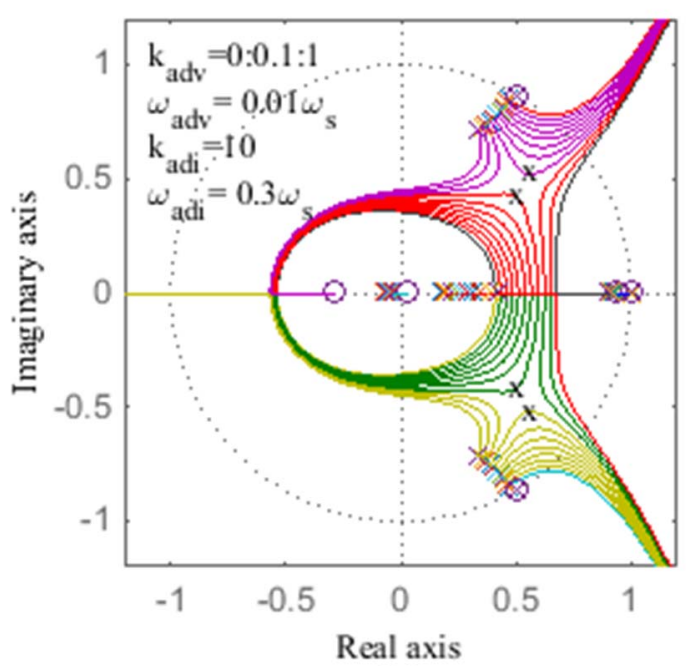

(b)

Fig. 9. Root loci of closed loop system. (a) Grid current active damping loop design (step 2). (b) Capacitor voltage active damping loop design (step 3).

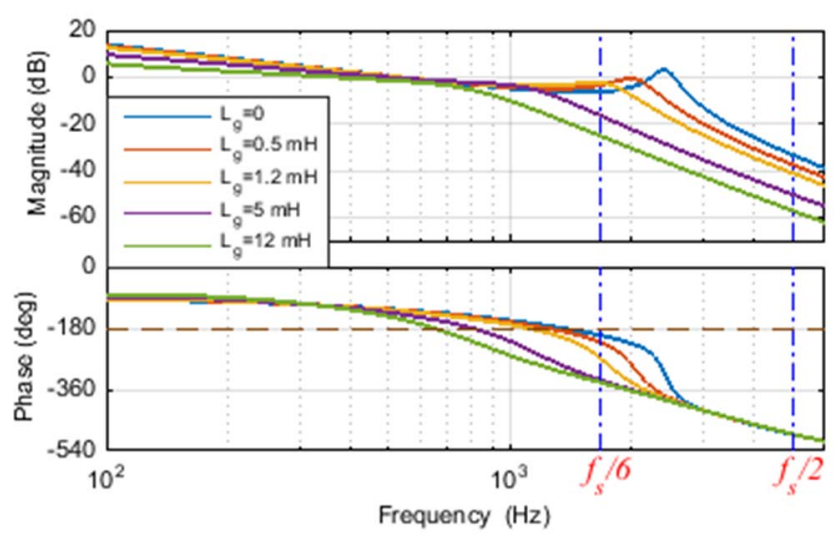

Fig. 10. Bode plot of the open loop TF, $G_{o l}$ with the proposed hybrid active damping method. 


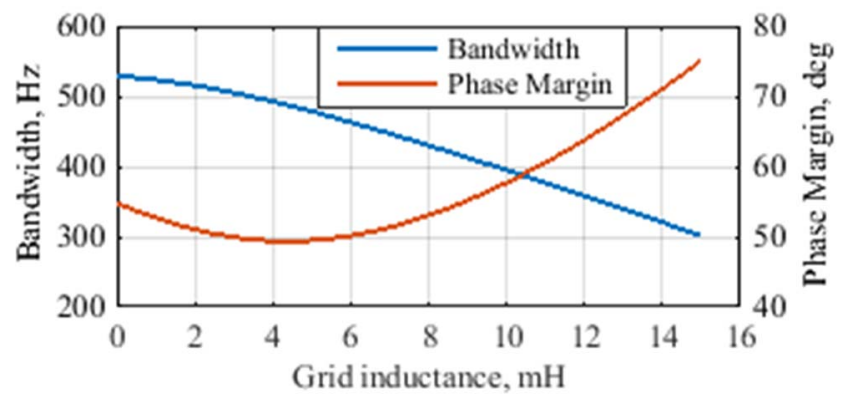

Fig. 11. System bandwidth and phase margin with the proposed hybrid active damping method.

\section{Harmonics rejection}

Background harmonics are a major component of the grid current. The transfer function from the grid voltage to the grid current is given by $Y_{e q}$ in (17). The bode plot of the converter output admittance without damping and with the proposed hybrid active damping is shown in Fig. 12. Based on the passivity theory [24], it can be seen that the single loop grid current control without damping is unstable below $f_{s} / 6$. In contrast, the grid current control with the proposed hybrid damping loop is stable over a wide frequency range. In addition, low order harmonic rejection is improved (see Fig. 12).

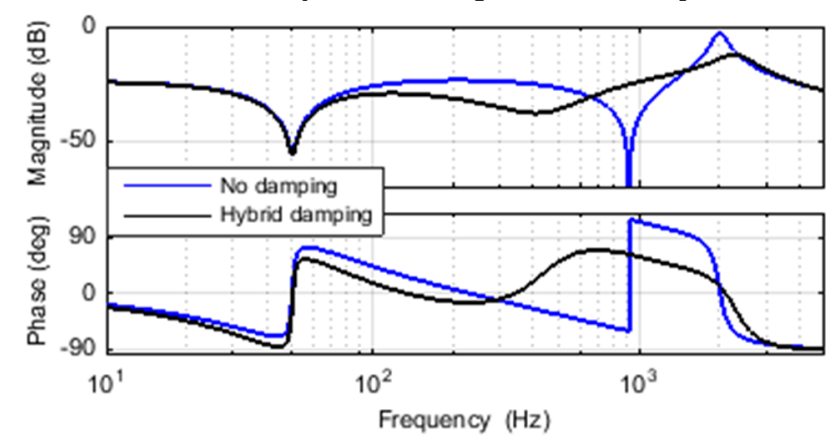

Fig. 12. Bode plot of the converter output admittance, $Y_{e q}$.

\section{SIMULATION RESULTS}

The proposed system was simulated in the Matlab/Simulink environment using system parameters of Table I. Results at different operating scenarios and different grid inductance are presented and discussed.

Fig. 13 shows the grid voltage and the injected grid current without the damping method and grid inductance of $0.5 \mathrm{mH}$ and the reference current is set at $10 \mathrm{~A}$. At $\mathrm{t}=1.005 \mathrm{~s}$, the reference current is increased to $20 \mathrm{~A}$ and at $\mathrm{t}=1.065 \mathrm{~s}$ it returns back to 10 A again. The system becomes marginally stable: the system will be unstable if the grid inductance is increased. Fig. 14 shows the results for grid inductance of $1.2 \mathrm{mH}$ with the proposed hybrid damping. The system is stable during the current reference change and the system response is fast enough due to the co-design method. Operation with high grid impedance (12mH-weak grid) was also performed and the results are presented in Fig. 15. The resonance is well damped and the system is stable even if the operating point is changed. The results agree with the analysis presented previously.

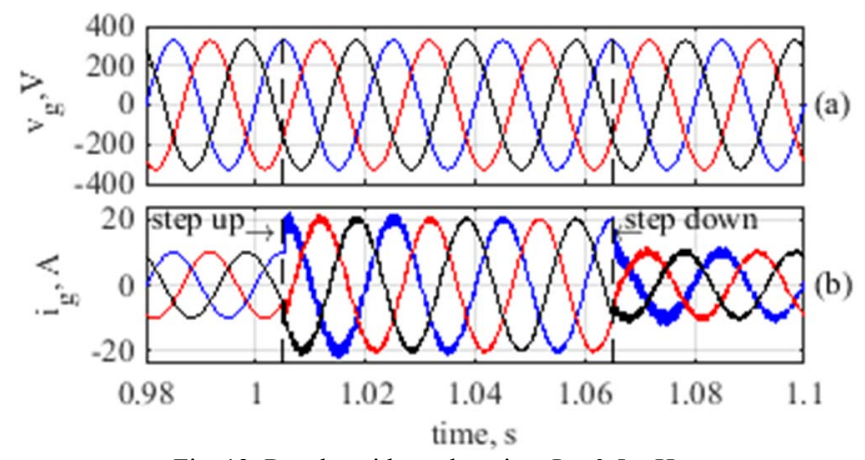

Fig. 13. Results without damping, $\mathrm{L}_{\mathrm{g}}=0.5 \mathrm{mH}$.

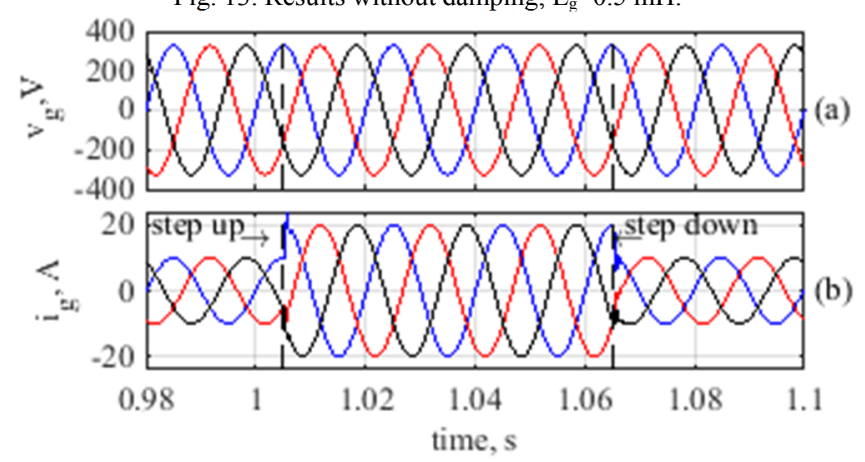

Fig. 14. Results with hybrid damping, $\mathrm{L}_{\mathrm{g}}=1.2 \mathrm{mH}$.

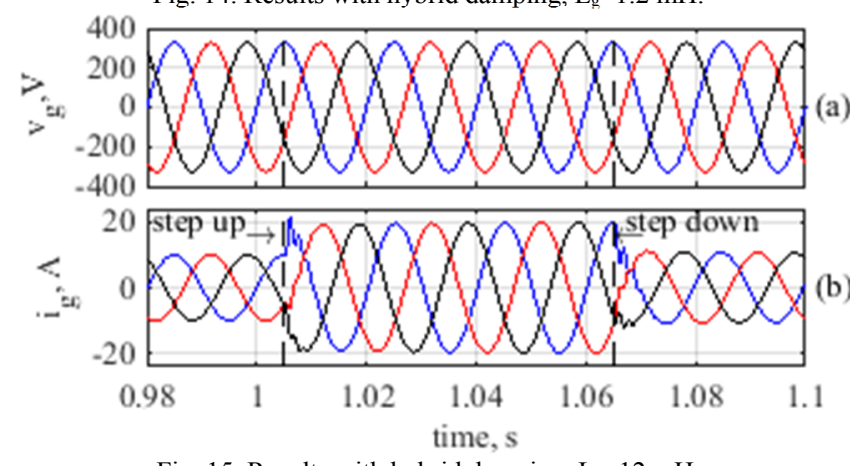

Fig. 15. Results with hybrid damping, $\mathrm{L}_{\mathrm{g}}=12 \mathrm{mH}$.

To investigate harmonic rejection, fifth and seventh harmonics of 5\% amplitude are added to the grid voltage and the results are presented in Fig. 16 and 17. From Fig. 16, the injected grid current is non-sinusoidal and the total harmonic distortion is more than $12 \%$ when no damping is included. Fig. 17 shows the same test after applying hybrid active damping. Obviously, the current waveforms are improved and the total harmonic distortion is significantly reduced, agreeing with Fig. 12.

\section{CONCLUSIONS}

A hybrid active damping method for $L C L$-filtered grid connected converters has been presented operating under weak grid conditions. In contrast to a single loop grid current control working without the $L C L$ resonance damping method, the proposed hybrid active damping method can guarantee system stability and effective suppression of the $L C L$ resonance over a wide grid inductance range. A recommended co-design procedure has been presented. Frequency domain analysis and MATLB/Simulink time domain simulations have been carried out and the results demonstrate the robustness and effectiveness of the proposed hybrid active method under different grid conditions. 

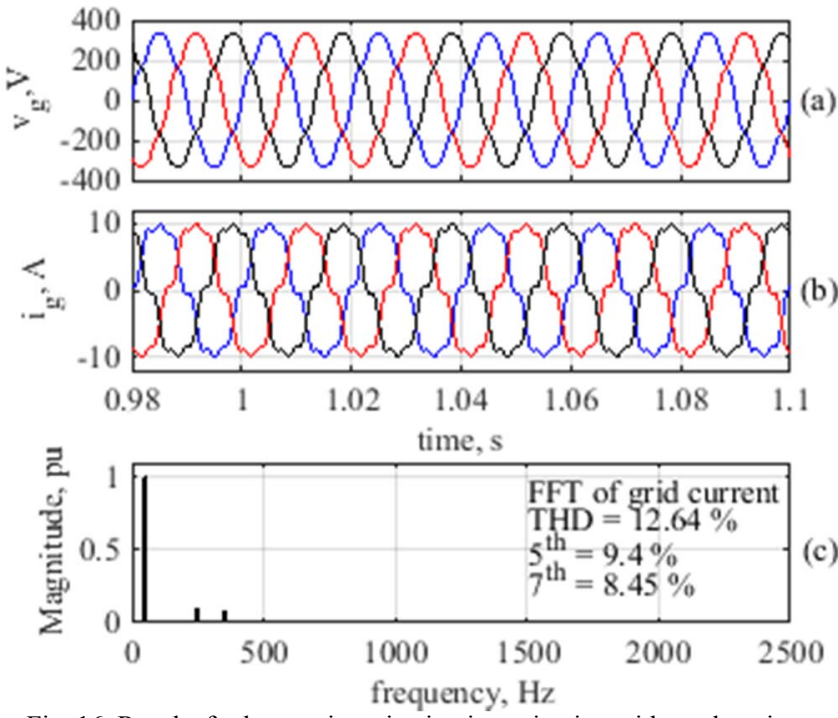

Fig. 16. Results for harmonics rejection investigation without damping
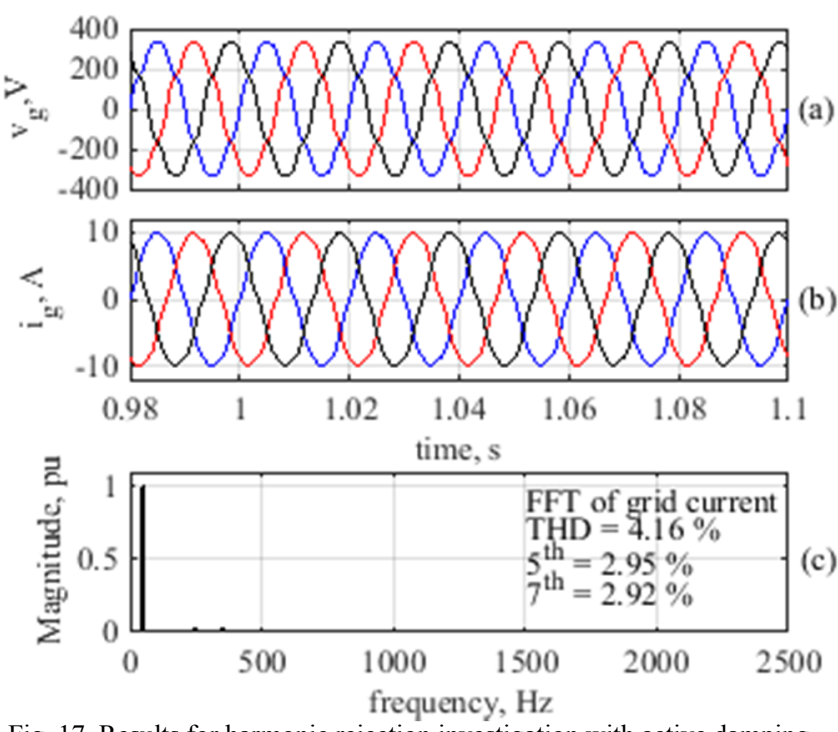

Fig. 17. Results for harmonic rejection investigation with active damping.

\section{ACKNOWLEGMENT}

This work was supported by Egyptian Government-ministry of higher education (cultural affairs and missions sector)- $\mathrm{PhD}$ scholarship. The authors gratefully acknowledge support from EPSRC through the IMASE project (Reference EP/K036297/1).

\section{REFERENCES}

[1] T. Erika and D. G. Holmes, "Grid current regulation of a three-phase voltage source inverter with an LCL input filter," Power Electronics, IEEE Transactions on, vol. 18, pp. 888-895, 2003.

[2] P. Donghua, R. Xinbo, B. Chenlei, L. Weiwei, and W. Xuehua, "Capacitor-current-feedback active damping with reduced computation delay for improving robustness of LCL-type grid-connected inverter," Power Electronics, IEEE Transactions on, vol. 29, pp. 3414-3427, 2014.

[3] T. Yi, L. Poh Chiang, W. Peng, C. Fook Hoong, and G. Feng, "Exploring inherent damping characteristic of LCL-filters for three-phase gridconnected voltage source inverters," Power Electronics, IEEE Transactions on, vol. 27, pp. 1433-1443, 2012.

[4] J. Wang and J. D. Yan, "Using virtual impedance to analyze the stability of LCL-filtered grid-connected inverters," in Industrial Technology (ICIT), 2015 IEEE International Conference on, 2015, pp. 1220-1225.
[5] Z. Bai, H. Ma, D. Xu, B. Wu, Y. Fang, and Y. Yao, "Resonance damping and harmonic suppression for grid-connected current-source converter," IEEE Transactions on Industrial Electronics, vol. 61, pp. 3146-3154, 2014.

[6] R. Beres, X. Wang, F. Blaabjerg, C. L. Bak, and M. Liserre, "Comparative evaluation of passive damping topologies for parallel grid-connected converters with LCL filters," in 2014 International Power Electronics Conference (IPEC-Hiroshima 2014 - ECCE ASIA), 2014, pp. 3320-3327.

[7] I. Lorzadeh, M. Savaghebi, H. A. Abyaneh, and J. M. Guerrero, "Active damping techniques for LCL-filtered inverters-based microgrids," in Diagnostics for Electrical Machines, Power Electronics and Drives (SDEMPED), 2015 IEEE 10th International Symposium on, 2015, pp. 408-414.

[8] J. Dannehl, C. Wessels, and F. W. Fuchs, "Limitations of voltage-oriented PI current control of grid-connected PWM rectifiers with LCL filters," IEEE Transactions on Industrial Electronics, vol. 56, pp. 380-388, 2009.

[9] C. Bao, X. Ruan, X. Wang, W. Li, D. Pan, and K. Weng, "Step-by-step controller design for LCL-type grid-connected inverter with capacitor current-feedback active-damping," IEEE Transactions on Power Electronics, vol. 29, pp. 1239-1253, 2014.

[10] X. Li, X. Wu, Y. Geng, X. Yuan, C. Xia, and X. Zhang, "Wide damping region for LCL-type grid-connected inverter with an improved capacitorcurrent-feedback method," IEEE Transactions on Power Electronics, vol. 30, pp. 5247-5259, 2015.

[11] D. Pan, X. Ruan, C. Bao, W. Li, and X. Wang, "Capacitor-currentfeedback active damping with reduced computation delay for improving robustness of LCL-type grid-connected inverter," IEEE Transactions on Power Electronics, vol. 29, pp. 3414-3427, 2014.

[12] Z. Xin, P. C. Loh, X. Wang, F. Blaabjerg, and Y. Tang, "Highly accurate derivatives for LCL-filtered grid converter with capacitor voltage active damping," IEEE Transactions on Power Electronics, vol. 31, pp. 3612$3625,2016$.

[13] W. Xiongfei, F. Blaabjerg, and L. Poh Chiang, "Virtual RC damping of LCL-filtered voltage source converters with extended selective harmonic compensation," Power Electronics, IEEE Transactions on, vol. 30, pp. 4726-4737, 2015.

[14] M. Malinowski and S. Bernet, "A simple voltage sensorless active damping scheme for three-phase PWM converters with an LCL filter," IEEE Transactions on Industrial Electronics, vol. 55, pp. 1876-1880, 2008.

[15] J. C. Wiseman and W. Bin, "Active damping control of a high-power PWM current-source rectifier for line-current THD reduction," IEEE Transactions on Industrial Electronics, vol. 52, pp. 758-764, 2005.

[16] X. Wang, F. Blaabjerg, and P. C. Loh, "Grid-current-feedback active damping for LCL resonance in grid-connected voltage-source converters," IEEE Transactions on Power Electronics, vol. 31, pp. 213-223, 2016.

[17] J. Xu, S. Xie, and T. Tang, "Active damping-based control for gridconnected LCL-filtered inverter with injected grid current feedback only," IEEE Transactions on Industrial Electronics, vol. 61, pp. 4746-4758, 2014.

[18] S. Eren, M. Pahlevaninezhad, A. Bakhshai, and P. K. Jain, "Composite nonlinear feedback control and stability analysis of a grid-connected voltage source inverter with LCL filter," IEEE Transactions on Industrial Electronics, vol. 60, pp. 5059-5074, 2013.

[19] J. R. Massing, M. Stefanello, H. A. Grundling, and H. Pinheiro, "Adaptive current control for grid-connected converters with LCL filter," IEEE Transactions on Industrial Electronics, vol. 59, pp. 4681-4693, 2012.

[20] J. Dannehl, F. W. Fuchs, S. Hansen, and P. B. Thogersen, "Investigation of active damping approaches for PI-based current control of gridconnected pulse width modulation converters with LCL filters," IEEE Transactions on Industry Applications, vol. 46, pp. 1509-1517, 2010.

[21] D. M. VandeSype, K. DeGusseme, F. M. L. L. DeBelie, A. P. VandenBossche, and J. A. Melkebeek, "Small-signal z -domain analysis of digitally controlled converters," IEEE Transactions on Power Electronics, vol. 21, pp. 470-478, 2006.

[22] S. G. Parker, B. P. McGrath, and D. G. Holmes, "Regions of active damping control for LCL filters," IEEE Transactions on Industry Applications, vol. 50, pp. 424-432, 2014.

[23] R. C. Dorf and R. H. Bishop, Modern control systems: Prentice Hall, 2011.

[24] L. Harnefors, L. Zhang, and M. Bongiorno, "Frequency-domain passivitybased current controller design," IET Power Electronics, vol. 1, pp. 455$465,2008$. 